\title{
Adenosine-Responsive Wide QRS Complex Tachycardia: What is the Mechanism?
}

\author{
HAKAN ORAL, M.D., GREGORY F. MICHAUD, M.D., and FRED MORADY, M.D. \\ From the Department of Internal Medicine, Division of Cardiology, University of Michigan, Ann Arbor, Michigan
}

\section{Case Presentation}

A 45-year-old man presented with an acute anterior wall myocardial infarction and underwent successful percutaneous transluminal angioplasty of the left anterior descending coronary artery. Twenty-four hours later, a wide QRS tachycardia at a rate of 108 beats/min that had a QRS duration of $150 \mathrm{msec}$ was noted by telemetric monitoring. There were no symptoms associated with the tachycardia. A 12-lead ECG was recorded (Fig. 1). The tachycardia terminated after infusion of $12 \mathrm{mg}$ of adenosine (Fig. $2)$. What is the mechanism of this adenosineresponsive wide QRS complex tachycardia?

\section{Commentary}

The ECG shown in Figure 1 demonstrates a wide QRS complex tachycardia at a rate of 108 beats/min that has a right bundle branch block configuration and right-axis deviation. There is a $\mathrm{P}$ wave immediately after each QRS complex (best seen in lead $V_{3}$ ), indicating either 1:1 AV conduction or 1:1 VA conduction (Fig. 1). The differential diagnosis at this point includes a supraventricular tachycardia (AV nodal reentrant tachycardia, orthodromic reciprocating tachycardia, atrial tachycardia, or automatic junctional tachycardia) with a rate-related or underlying right bundle branch block, and ventricular tachycardia.

The response to adenosine shown in Figure 2 establishes the mechanism of this tachycardia.

J Cardiovasc Electrophysiol, Vol. 10, pp. 1688-1689, December 1999.

Address for correspondence: Fred Morady, M.D., Division of Cardiology, University of Michigan Medical Center, 1500 East Medical Center Drive, B1F245, Ann Arbor, MI 48109-0022. Fax: 734-936-7026.

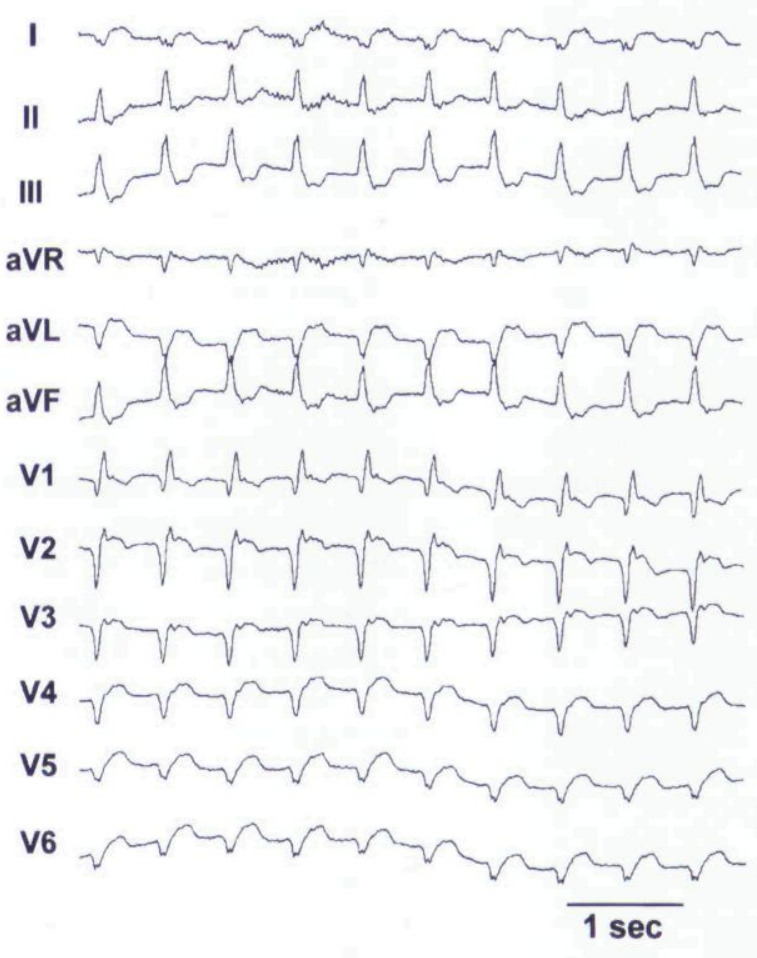

Figure 1. ECG recorded at the onset of the wide QRS complex tachycardia.

After the administration of adenosine, the 1:1 AV relationship is replaced by AV dissociation (again best seen in lead $\mathrm{V}_{3}$ ). This excludes orthodromic reciprocating tachycardia and atrial tachycardia and narrows the list of possibilities to AV nodal reentrant tachycardia (probably a very rare response to adenosine), automatic junctional tachycardia, and ventricular tachycardia. Note that there is a supraventricular capture beat just before the tachycardia terminates, and that this QRS complex is narrow. This indicates that the wide QRS complexes recorded during the tachycardia cannot be attributed to a rate-related 


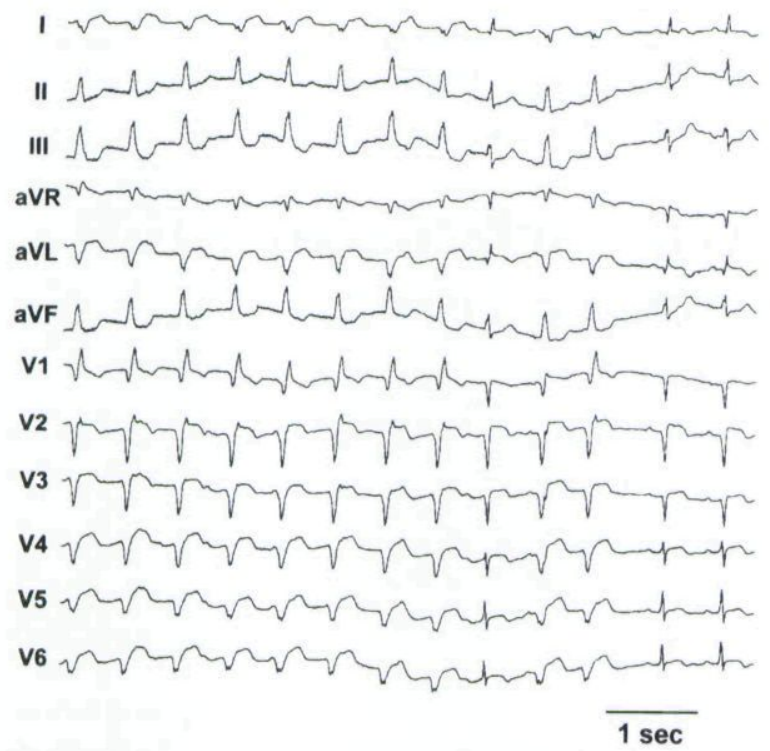

Figure 2. ECG recorded several seconds after infusion of $12 \mathrm{mg}$ of adenosine. or underlying right bundle branch block. Therefore, the tachycardia is a ventricular tachycardia.

Adenosine-sensitive ventricular tachycardia primarily is due to cyclic adenosine monophosphate-mediated triggered activity. ${ }^{1,2}$ In patients with coronary artery disease, monomorphic ventricular tachycardia usually is caused by reentry. In this patient, ventricular tachycardia probably was caused by ischemia- or reperfusion-induced triggered activity.

\section{References}

1. Lerman BB, Belardinelli L, West GA, et al: Adenosine sensitive ventricular tachycardia: Evidence suggesting cAMP-mediated triggered activity. Circulation 1986;74: 270-280.

2. Lerman BB: Response of nonreentrant catecholaminemediated ventricular tachycardia to endogenous adenosine and acetylcholine. Evidence for myocardial receptor-mediated effects. Circulation 1993;87:382-390. 
This document is a scanned copy of a printed document. No warranty is given about the accuracy of the copy. Users should refer to the original published version of the material. 